\title{
Evaluation of the Mechanical Properties of Microcapsule-Based Self-Healing Composites
}

\author{
Liberata Guadagno, ${ }^{1}$ Marialuigia Raimondo, ${ }^{1}$ Umberto Vietri, ${ }^{1}$ Carlo Naddeo, ${ }^{1}$ \\ Anja Stojanovic, ${ }^{2}$ Andrea Sorrentino, ${ }^{3}$ and Wolfgang H. Binder ${ }^{2}$ \\ ${ }^{1}$ Department of Industrial Engineering, University of Salerno, Via Giovanni Paolo II, 132-84084 Fisciano, Italy \\ ${ }^{2}$ Faculty of Natural Sciences II, Institute of Chemistry, Chair of Macromolecular Science, Martin Luther University of Halle-Wittenberg, \\ von-Danckelmann-Platz 4, 06120 Halle (Saale), Germany \\ ${ }^{3}$ Institute for Polymers Composites and Biomaterials (IPCB), CNR, Piazzale Enrico Fermi 1, 80055 Portici, Italy
}

Correspondence should be addressed to Liberata Guadagno; lguadagno@unisa.it and Marialuigia Raimondo; mraimond@unisa.it

Received 1 July 2015; Revised 20 November 2015; Accepted 13 January 2016

Academic Editor: Hong Nie

Copyright ( $\odot 2016$ Liberata Guadagno et al. This is an open access article distributed under the Creative Commons Attribution License, which permits unrestricted use, distribution, and reproduction in any medium, provided the original work is properly cited.

Self-healing materials are beginning to be considered for applications in the field of structural materials. For this reason, in addition to self-healing efficiency, also mechanical properties such as tensile and compressive properties are beginning to become more and more important for this kind of materials. In this paper, three different systems based on epoxy-resins/ethylidene-norbornene (ENB)/Hoveyda-Grubbs 1st-generation (HG1) catalyst are investigated in terms of mechanical properties and healing efficiency. The experimental results show that the mechanical properties of the self-healing systems are mainly determined by the chemical nature of the epoxy matrix. In particular, the replacement of a conventional flexibilizer (Heloxy 71) with a reactive diluent (1,4butanediol diglycidyl ether) allows obtaining self-healing materials with better mechanical properties and higher thermal stability. An increase in the curing temperature causes an increase in the elastic modulus and a slight reduction of the healing efficiency. These results can constitute the basis to design systems with high regenerative ability and appropriate mechanical performance.

\section{Introduction}

Highly cross-linked polymeric materials are generally needed to obtain mechanical strengths necessary for structural applications. Unfortunately, as the degree of cross-linking increases, the material generally tends to become brittle and therefore more prone to the development of fatigue cracking. For this reason, the development of self-healing materials able to protect the structural materials by the advance of dangerous microlesions is very important. These materials promise to increase the structural performance, reducing the weight and size of the resulting parts, while maintaining the safety. Several concepts for developing structural polymer composites with self-repairing properties have recently been proposed [1]. The first example of a self-mendable system consists of a microencapsulated healing agent homogeneously dispersed within an epoxy matrix [2].
For this kind of system, during the microcrack propagation, the intercepted microcapsules are damaged with subsequent leakage of the repairing agent [2-9].

Autorepair reaction via a Ring Opening Metathesis Polymerization (ROMP) is promoted by the catalyst embedded in the matrix [9-19]. These systems are based on Grubbs' first-generation (G1) catalyst [8,20-23] and other Grubbs and Hoveyda-Grubbs ruthenium catalysts (G2, HG1, and HG2) [9, 24-29]. Self-healing systems based on ROMP reactions can be very efficient in rigid polymers such as epoxy structural cross-linked resins. However, some drawbacks are actually under reevaluation in order to enable the development of advanced materials. Probably, the most important one regards the thermal stability of the ruthenium catalysts [24, 26]. In fact, at the high temperatures of the processing steps (especially for structural applications), thermolytic decomposition can impair the activity of the ruthenium catalyst. 
In common structural applications, a glass transition temperature higher than $100^{\circ} \mathrm{C}$ is required. In order to ensure an efficient cross-linking degree, the curing temperature for these materials must be higher than $100^{\circ} \mathrm{C}$ of several Celsius degrees. For example, a post curing treatment at temperatures that could be as high as $150-180^{\circ} \mathrm{C}$ is not unusual for these systems.

It is worth noting that ROMP reaction is affected by the chemical nature of both the catalyst and the healing agent [9]. Activity, healing efficiency, and temperature of metathesis activation are closely related to the specific combination chosen to formulate the autorepair material [9].

In the present paper, in order to formulate self-healing systems active even at low temperature $[9,30]$, ethylidenenorbornene (ENB) as "healing agent" and Hoveyda-Grubbs 1st-generation (HG1) catalyst, in the form of molecular complex, are chosen. The effects of the epoxy formulation and the curing cycle on the restorative effectiveness and dynamic mechanical behavior of self-repairing epoxy-resins are reported by Guadagno and coworkers in a recent paper [9]. In light of the previous promising results [9], in the present paper the authors analyze the tensile and compression properties of these systems together with aspects related to their thermal stability, with the aim of evaluating relevant properties for practical applications.

\section{Experimental}

2.1. Materials. In the attempt to formulate an efficient selfhealing system, three different systems, namely, EHA, EBA1, and EBA2, with the same design are investigated and compared. They differ in the nature and composition of the epoxy matrix.

2.1.1. Epoxy Matrices. All the developed systems contain Epon 828 (E) and Ancamine K 54 (A) in their formulations. The difference between the EBA and EHA formulations is in the chemical nature of the flexibilizer.

EHA formulation is prepared by mixing the epoxy-resin (E) with Heloxy $71(\mathrm{H})$ in a percentage of $37 \%$ by weight. The same formulation was already proposed for a self-healing system already described in literature $[4,8]$.

$E B A 1$ formulation is prepared by mixing the epoxyresin (E) with a reactive diluent (1,4-butanediol diglycidyl ether) (B) at a concentration of 90:10 (by \%wt) epoxide to flexibilizer.

EBA2 formulation is prepared by mixing the epoxy-resin (E) with the 1,4-butanediol diglycidyl ether at a concentration of $80: 20$ (by \%wt) epoxide to flexibilizer.

The hardener agent $(\mathrm{A})$ investigated in this paper is 2,4,6tris(dimethylamino) methyl-phenol (trade name Ancamine $\mathrm{K} 54)$.

The catalyst Hoveyda-Grubbs' 1st-generation (HG1) (purchased from Aldrich), before dispersion into the epoxy matrix, is reduced in thin powder with an average dimension of the catalyst bars of $15 \times 5 \mu \mathrm{m}$.

2.1.2. Microcapsules Manufacture. Microcapsules (Mic) of 5-ethylidene-2-norbornene (ENB) are prepared by in situ polymerization in an oil-in-water emulsion. They have a double shell composed by an outer layer of poly(ureaformaldehyde) and an inner layer of ethylene maleic anhydride (EMA) copolymer [27].

The preparation is started by dissolving at room temperature $100 \mathrm{~mL}$ of EMA copolymer (2.5 wt\% aqueous solution) in $400 \mathrm{~mL}$ of distilled water. The mixing is continued at $100^{\circ} \mathrm{C}$ until a perfectly clear solution is obtained. The temperature is carefully controlled by means of a digital stirring hotplate with external temperature immersion probe (Dataplate Digital Hotplate, Cole Palmer). Uniform and homogeneous stirring is guaranteed by high shear digital mixer/emulsifier (Silverson Machines Ltd.) driving a three-bladed, $63.5 \mathrm{~mm}$ diameter low-shear mixing propeller (Cole Parmer) placed just above the bottom of the beaker containing the emulsion.

Under continuous stirring at $1800 \mathrm{rpm}$, the solution is added with one gram of ammonium chloride, one gram of resorcinol, and ten grams of urea. The $\mathrm{pH}$ (measured with a pH-Meter BASIC 20 by Crison Instruments) is kept in the range of $3.50-3.60$ by dropwise addition of $10 \% \mathrm{NaOH}$ solution. Surfactant 1-octanol is used. After stabilization of the droplets, about twenty-five grams of $37 \mathrm{wt} \%$ aqueous solution of formaldehyde is added. The stirring rate is then lowered to $1000 \mathrm{rpm}$ and the temperature lowered to $55^{\circ} \mathrm{C}$ at a rate of $1^{\circ} \mathrm{C} / \mathrm{min}$. After about $4 \mathrm{~h}$ of continuous agitation, the obtained suspension is allowed to slowly cool down to room temperature without agitation. The resulting suspension is filtered and washed several times with deionized water. Before use, the microcapsules are finally dried at ambient temperature for $48 \mathrm{~h}$.

2.1.3. Samples Preparation. The self-healing mixtures are obtained by dispersing $10 \mathrm{wt} \%$ of microcapsules containing ENB and $5 \mathrm{wt} \%$ of finely pulverized catalyst into the epoxyresin components. The solution is accurately mixed by mechanical agitation avoiding the formation of air bubbles. A mold cavity is then carefully filled and leveled with the liquid mixture.

Two stages of curing cycles are performed: a first isothermal stage at $125^{\circ} \mathrm{C}$ for $2 \mathrm{~h}$ followed by a second isothermal stage for $2 \mathrm{~h}$ at higher temperature. Two series of samples are prepared by choosing the temperature of $170^{\circ} \mathrm{C}$ and $180^{\circ} \mathrm{C}$ for the second isothermal stage. After a slow cooling, the samples are taken out of the mold and examined. For each condition, at least five different samples are taken each for compression, tensile, and dynamic mechanical tests.

2.2. Methods. Thermogravimetric analysis (TGA) is carried out with a thermobalance (Mettler TGA/SDTA 851) by recording the weight loss as a function of temperature. Resin samples are heated from 30 to $1000^{\circ} \mathrm{C}$ at $10^{\circ} \mathrm{C} / \mathrm{min}$ under air flow. Tensile and compression measurements are carried out on an Instron universal tester model 4301 with 1 and $10 \mathrm{kN}$ load cells. Dogbone tensile specimens in accordance with ASTM D638 (type V) are used to measure the tensile properties. The compression test samples are cut with dimensions of about $10 \times 4 \times 10 \mathrm{~mm}^{3}$. Both types of measurements are carried out at a rate of $1 \mathrm{~mm} / \mathrm{min}$ at room temperature. The 
results are reported as the average and standard deviation of at least five samples.

Dynamic mechanical properties are measured using a Q800 Dynamic Mechanical Thermal Analyzer (TA Instruments). The width, thickness, and length of the specimen are 10,4 , and $80 \mathrm{~mm}$, respectively. The test temperatures are from -30 to $70^{\circ} \mathrm{C}$, with the heating rate of $3^{\circ} \mathrm{C} / \mathrm{min}$, the frequency of $1 \mathrm{~Hz}$, and the strain equal to $0.1 \%$.

Crack healing efficiency $(\eta)$ defined as the ability of a healed sample to recover fracture toughness [31] can be defined for quasi-static fracture conditions by means of the following equation:

$$
\eta=\frac{K_{\mathrm{IC} \_ \text {healed }}}{K_{\mathrm{IC} \_ \text {virgin }}},
$$

where $K_{\text {IC_virgin }}$ is the fracture toughness of the virgin specimen and $K_{\text {IC_healed }}$ is the fracture toughness of the healed specimen. The protocol used to measure the crack healing efficiency of both the virgin and the healed samples is described elsewhere $[2,31]$. In particular, samples with modified tapered double cantilever beam (TDCB) geometry are used [32]. This geometry ensures the controlled crack growth of a precrack intentionally introduced in the specimen. After crack propagation until sample failure, the sample is removed by the load frame and allowed to heal at room temperature with no external intervention. After $24 \mathrm{~h}$ of healing, the sample is mounted on the load frame and loaded again under displacement control. By considering that

$$
K_{\mathrm{IC}}=\alpha P_{\mathrm{C}},
$$

where $P_{C}$ is the critical fracture load and $\alpha$ is a geometry factor equal to $11.2 \times 10^{3} \mathrm{~m}^{-3 / 2}$ for the TDCB geometry used $[2,31-33]$, the efficiency measurement can be obtained by the following equation:

$$
\eta=\frac{P_{C_{\text {_healed }}}}{P_{C_{-} \text {virgin }}}
$$

Scanning electron microscopy (SEM) micrographs are obtained with a LEO 1525 microscope. The samples are covered with a $250 \AA$ thick gold film using a sputter coater (Agar mod. $108 \mathrm{~A}$ ).

\section{Results}

3.1. Microcapsule Characterization. A representative scanning electron microscopy (SEM) micrograph of the surface morphology of the synthesized microcapsules is shown in Figure 1. As evident by the micrograph, the microcapsules show a rough texture of the walls. They seem to be snarls of tubular nanovessels as already found in a previous paper [9]. Thermal analysis reported elsewhere [28] shows that these microcapsules, heated up to $180^{\circ} \mathrm{C}$, have a good thermal and chemical stability. In fact, mechanical rupture of the urea/formaldehyde double shell, with the leakage of the polymerizer agent, started only at temperatures higher than $200^{\circ} \mathrm{C}[28]$. This result has been also considered as an indirect
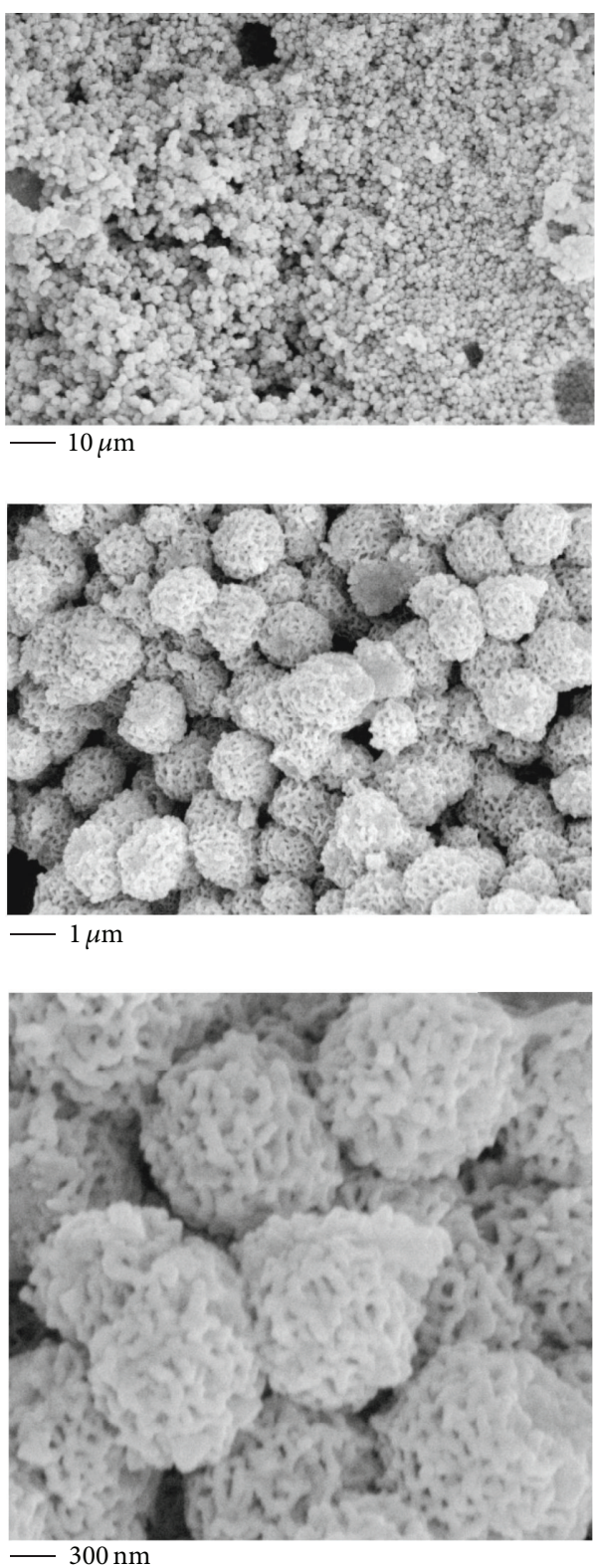

FIGURE 1: SEM micrograph of the obtained microcapsules.

confirmation of the presence of the healing agent in the microcapsules. Furthermore, the presence of 5-ethylidene-2norbornene (ENB) inside the tubular nanovessels has been also verified by means of ${ }^{1} \mathrm{H}$ NMR spectroscopy and gasliquid chromatography [9].

\subsection{Mechanical Properties}

3.2.1. Tensile Properties. In Figures 2(a)-2(c), representative tensile stress-strain curves (one for each material system analyzed) are presented. For comparison, in Figure 2, the trends observed for the neat resin are also reported. All samples fail in the gage section; samples EBA1 and EBA2 show a brittle behavior, whereas the EHA samples show a nonlinearity at the end of the elastic region. This viscoelastic 


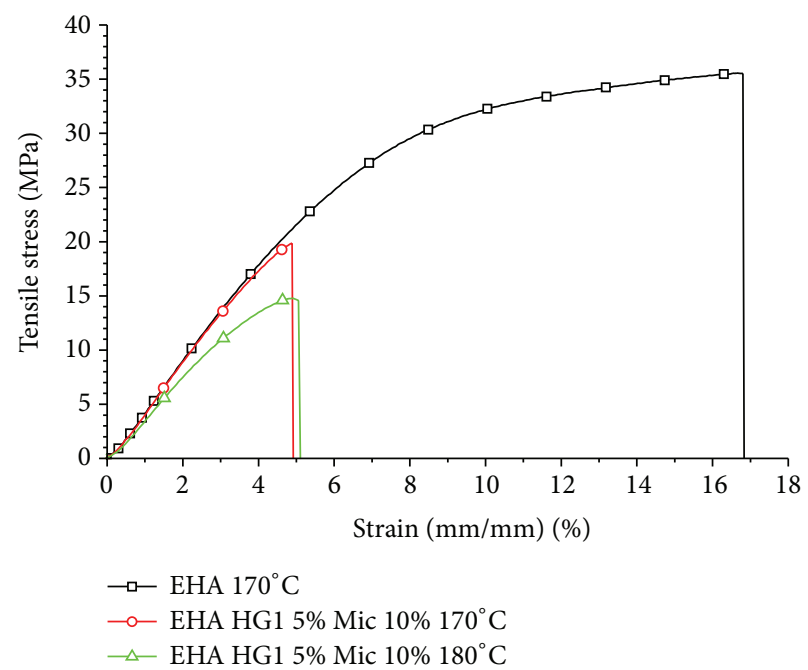

(a)

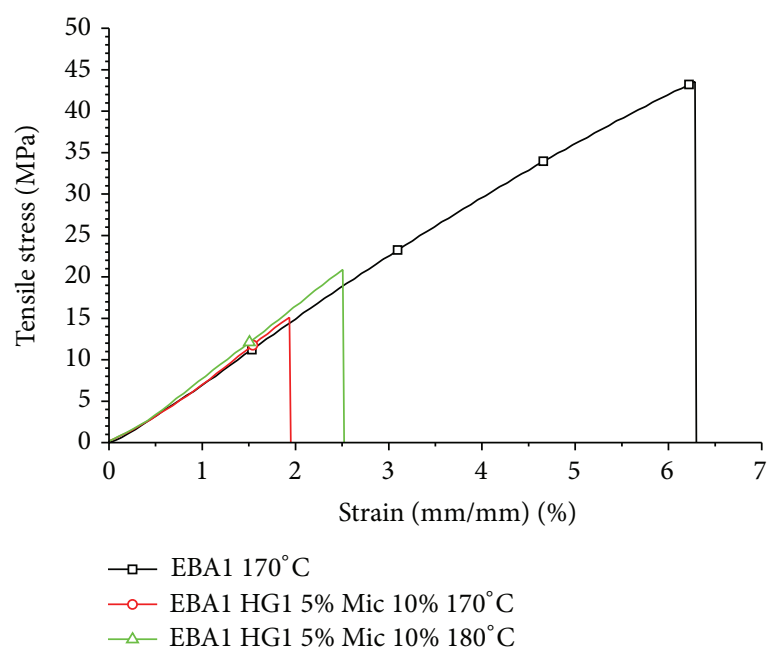

(b)

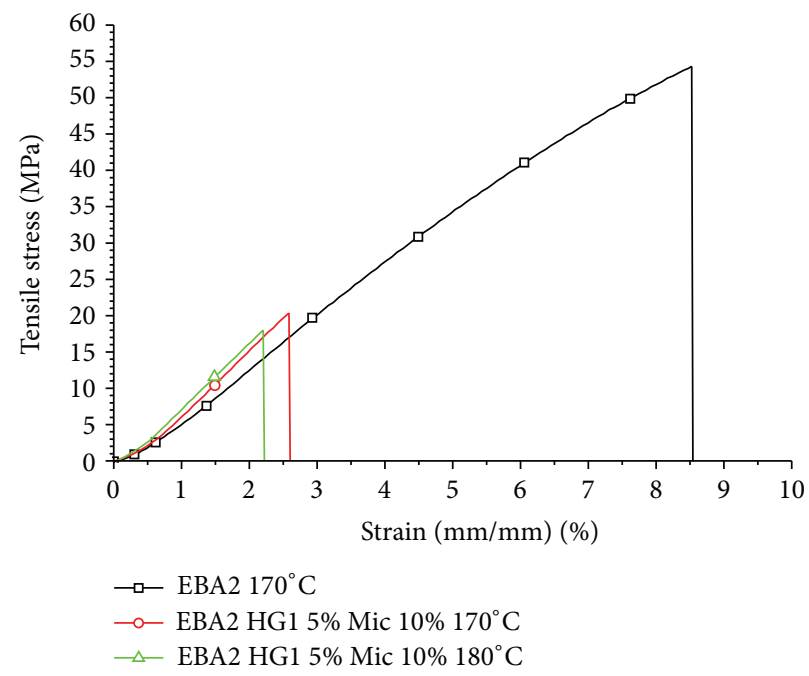

(c)

Figure 2: (a) Comparison of tensile stress-strain curves for neat EHA and EHA self-healing system at the different curing temperature. (b) Comparison of tensile stress-strain curves for neat EBA1 and EBAl self-healing system at the different curing temperature. (c) Comparison of tensile stress-strain curves for neat EBA2 and EBA2 self-healing system at the different curing temperature.

behavior is probably due to the presence of the flexibilizer (Heloxy 71) in the sample composition. In all samples, the presence of the capsules strongly reduces the elongation to break while the modulus is increased. This behavior is a clear evidence of the embrittlement effects caused by the embedded self-healing components. A reinforcing effect due to the microcapsule inclusion is already reported in literature for a self-healing formulation obtained using EHA as epoxy matrix and Grubbs' first-generation catalyst and DCPD-filled microcapsules as self-healing components [3]. In particular, it is found that the presence of catalyst powder alone (without microcapsules) causes a slight decrease in the storage modulus value with respect to the epoxy matrix alone. This effect is ascribed to the increase in the cross-linking density. The different formulations analyzed in this paper seem to confirm this trend.
A cured epoxy-resin presents a distribution of molecular weights or segment lengths between the cross-linking points. In addition, the presence of unreacted monomers entrapped in the polymer network induces a decrease in the elastic modulus and an increase in the chain mobility that in turn impart to the sample properties closer to those of thermoplastic polymers. This effect is particularly important in the systems containing flexibilizer Heloxy 71. It seems to explain the stress-strain curve trend of these samples and also their lower elastic modulus. On the contrary, the reactive diluent is able to significantly reduce the extent of nonreacted segments in the network. The use of a reactive diluent also reduces the molecular distribution of the chains between cross-linking points.

In Table 1, tensile properties of different neat epoxy matrix formulations cured at $170^{\circ} \mathrm{C}$ are reported. As generally 


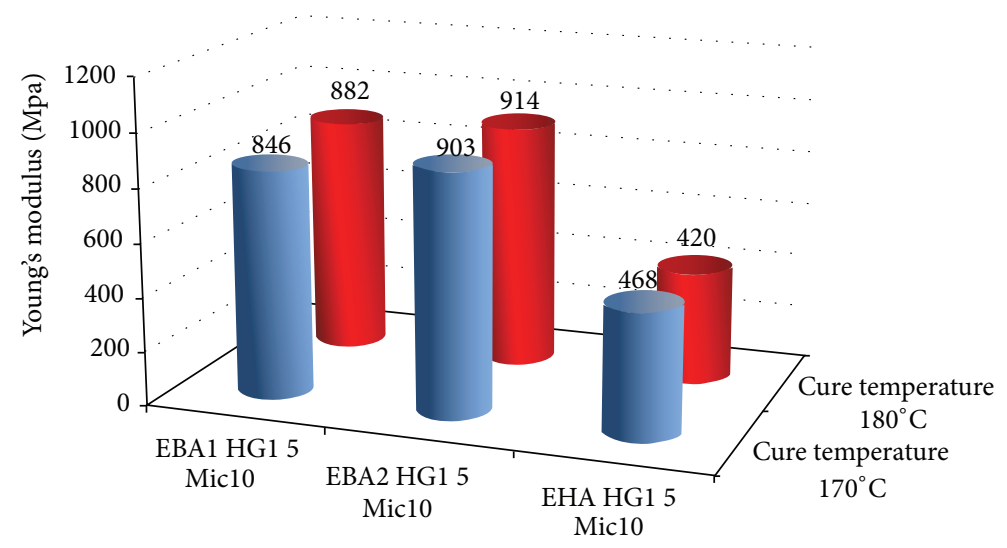

FIGURE 3: Young's modulus of self-healing epoxy formulations at different curing temperature of $170^{\circ} \mathrm{C}$ and $180^{\circ} \mathrm{C}$.

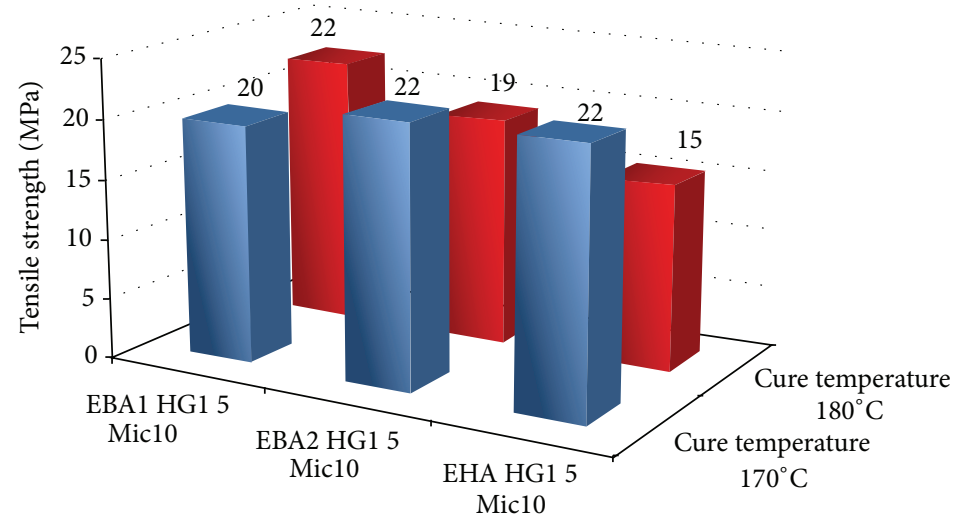

FIgURE 4: Tensile strength of self-healing epoxy formulations at different curing temperature of $170^{\circ} \mathrm{C}$ and $180^{\circ} \mathrm{C}$.

TABLE 1: Tensile properties of EHA, EBA1, and EBA2 at $170^{\circ} \mathrm{C}$.

\begin{tabular}{lccc}
\hline & EHA 170 & EBA1 170 & EBA2 170 \\
\hline Young's modulus [MPa] & $448( \pm 15)$ & $767( \pm 10)$ & $765( \pm 15)$ \\
Toughness [MPa] & $4.271( \pm 0.2)$ & $1.390( \pm 0.1)$ & $2.377( \pm 0.1)$ \\
Tensile strength [MPa] & $36( \pm 9)$ & $48( \pm 5)$ & $55( \pm 7)$ \\
Strain at break [\%] & $17.5 \%( \pm 2.5 \%)$ & $7 \%( \pm 1.5 \%)$ & $8.5 \%( \pm 1.5 \%)$ \\
\hline
\end{tabular}

expected with a brittle material, significant scatter in the ultimate tensile stress and the failure strain data is observed. However, the calculated Young's modulus of the material is more consistent within each sample system series.

In Figures 3-6, a summary of the tensile properties of the self-healing systems is presented. In particular, in Figure 3 the effect of curing temperature on Young's modulus of different formulations is reported. Samples based on the EBA matrices show Young's modulus higher than those detected for the sample based on the EHA matrix. The behavior of these selfhealing systems is strictly correlated to the nature of the epoxy matrix.

The increase in curing temperature leads to the increase in Young's modulus for the EBA based systems. On the opposite, a decrement of the Young's modulus is observed for EHA formulation as curing temperature increases. Probably, in this case, the high percentages of aliphatic segments in the cured network do not allow further formation of crosslinking points between the polymer chains.

The increase in the percentage of reactive diluent in the formulations EBA1 and EBA2 has opposite effects at the two curing temperature investigated. At $170^{\circ} \mathrm{C}$ it causes an increase in the tensile strength (see Figure 4) whereas, at $180^{\circ} \mathrm{C}$, an evident decrease is observed. Also, for the EHA sample, an increase in the curing temperature produces a sensible reduction of the tensile strength.

In Figure 5, the effect of curing temperature on strain at break of the different self-healing epoxy formulations is shown. At $170^{\circ} \mathrm{C}$, for EBA1 and EBA2 samples, no significant change in the tensile strain at break is observed. As shown by the noticeable values of this parameter for both curing temperatures, the presence of the flexibilizer in the EHA formulation produces the best tensile behavior. The lower strain values are measured at the highest curing temperature of $180^{\circ} \mathrm{C}$ and among the analyzed formulations the EBA2 samples display the lowest.

A similar behavior is observed for the effect of curing temperature on the toughness of the different self-healing formulations (Figure 6). In fact, at $170^{\circ} \mathrm{C}$, the EHA samples show higher toughness values than that of the EBA 2 and EBA1 formulations. At $180^{\circ} \mathrm{C}$, lower toughness values are measured 


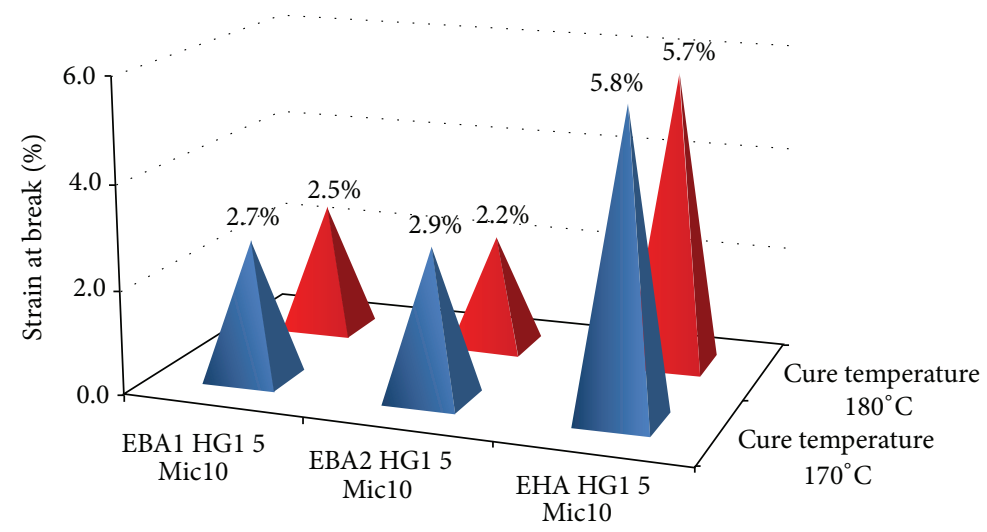

FIGURE 5: Strain at break of self-healing epoxy formulations at different curing temperature of $170^{\circ} \mathrm{C}$ and $180^{\circ} \mathrm{C}$.

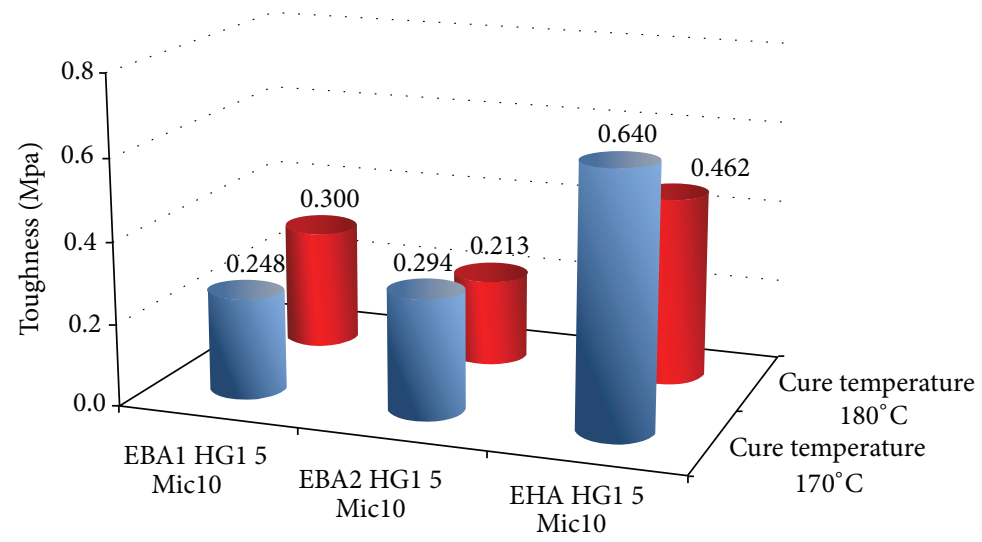

FIGURE 6: Toughness of self-healing systems with different epoxy matrices at different curing temperature of $170^{\circ} \mathrm{C}$ and $180^{\circ} \mathrm{C}$.

for all the samples; in particular EBA2 toughness value goes down with respect to the other samples.

3.2.2. Compressive Properties. In Figures 7(a)-7(c), representative compressive stress-strain curves (one for each material system analyzed) are presented. Also, for this type of tests, the trend observed for the neat resin is shown for comparison. The neat resin and the respective self-healing systems show similar stress-strain profiles consisting of a linear elastic region followed by a strain softening region. Large compressive strain is generally desirable because it results in high energy absorption and delayed material failure. In Table 2, compressive moduli, determined as the slope of the initial linear region of the stress-strain graphs, are presented. The results show that the compressive modulus of samples increases with increasing the curing temperature for the EBA formulations, with an adverse trend observed for the formulation EHA. This trend is similar to that observed for the tensile properties. In addition, also for the compressive modulus, the values detected for the EBA formulations are always higher than those detected for the EHA formulations. It is also seen that the modulus increases by passing from the neat resins to the respective self-healing systems. The moduli of systems EBA1 and EBA2 are 10-20\% higher than the neat resin tested at the same compression rate. For the EHA system, the effect of the capsules as well as the curing
TABLE 2: The compressive modulus values.

\begin{tabular}{lcc}
\hline Sample & $\begin{array}{c}\text { Compression } \\
\text { modulus }[\mathrm{MPa}]\end{array}$ & $\begin{array}{c}\text { Max stress } \\
{\left[\mathrm{KN} / \mathrm{mm}^{2}\right]}\end{array}$ \\
\hline EBA1-170 ${ }^{\circ} \mathrm{C}$ & 1211 & 92 \\
EBA2-170 ${ }^{\circ} \mathrm{C}$ & 1233 & 86 \\
EBA1_HG1_5_Mic10-170 ${ }^{\circ} \mathrm{C}$ & 1374 & 100 \\
EBA1_HG1_5_Mic10-180 ${ }^{\circ} \mathrm{C}$ & 1410 & 92 \\
EBA2_HG1_5_Mic10-170 $\mathrm{C}$ & 1405 & 93 \\
EBA2_HG1_5_Mic10-180 ${ }^{\circ} \mathrm{C}$ & 1443 & 97 \\
EHA-170 ${ }^{\circ} \mathrm{C}$ & 746 & 60 \\
EHA_HG1_5_Mic10-170 ${ }^{\circ} \mathrm{C}$ & 759 & 51 \\
EHA_HG1_5_Mic10-180 ${ }^{\circ} \mathrm{C}$ & 645 & 31 \\
\hline
\end{tabular}

temperature on the compressive properties is not so clear. Probably, in this case the effect of the flexibilizer (Heloxy 71) hinders the reinforcing mechanisms. However, these results indicate that the compressive strain can be tailored over a wide range by selecting appropriate curing temperature and flexibilizer volume fractions.

The features of self-healing specimens are similar to those presented by the neat resins counterpart, which include initiation of shear cracks and formation of fragments from 


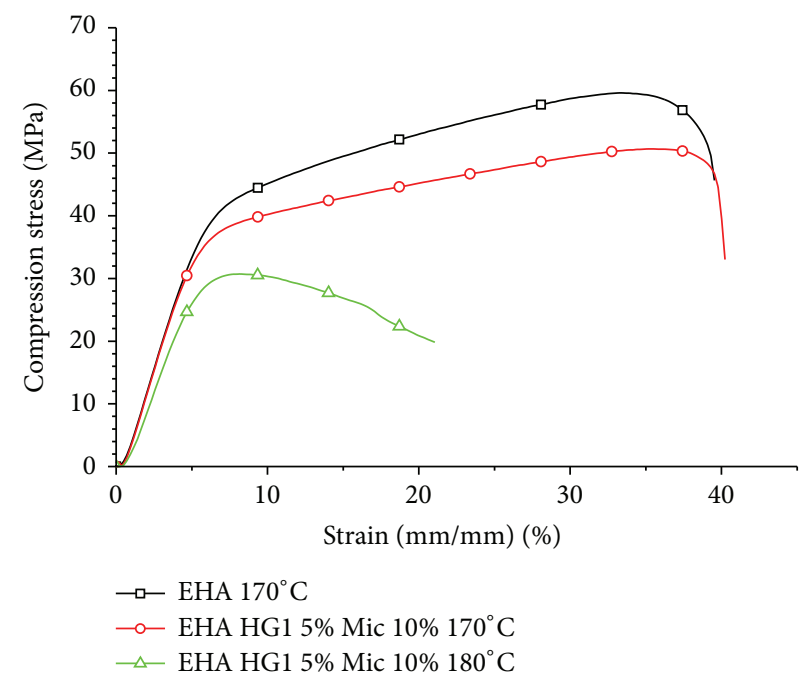

(a)

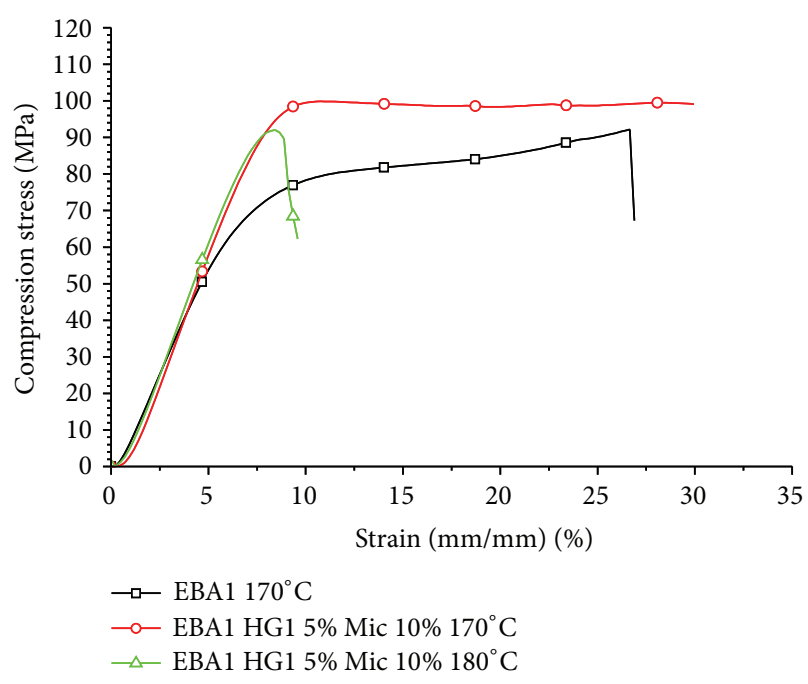

(b)

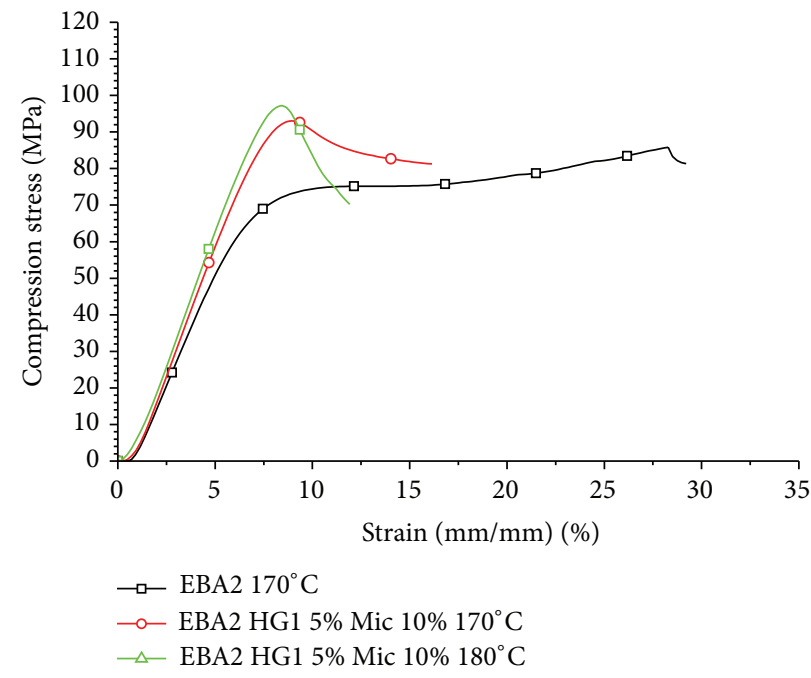

(c)

FIgURE 7: (a) Comparison of compressive stress-strain curves for neat EHA and for self-healing systems with EHA epoxy matrix, at the different curing temperature. (b) Comparison of compressive stress-strain curves for neat EBA1 and for self-healing systems with EBA1 epoxy matrix, at the different curing temperature. (c) Comparison of compressive stress-strain curves for neat EBA2 and for self-healing systems with EBA2 epoxy matrix, at the different curing temperature.

TABLE 3: Dynamic elastic moduli for self-healing formulation in the range of temperature between -30 and $70^{\circ} \mathrm{C}$.

\begin{tabular}{lccccccc}
\hline Sample & $E_{-30^{\circ} \mathrm{C}}^{\prime}[\mathrm{MPa}]$ & $E_{-10^{\circ} \mathrm{C}}^{\prime}[\mathrm{MPa}]$ & $E_{0^{\circ} \mathrm{C}}^{\prime}[\mathrm{MPa}]$ & $E_{+10^{\circ} \mathrm{C}}^{\prime}[\mathrm{MPa}]$ & $E_{+30^{\circ} \mathrm{C}}^{\prime}[\mathrm{MPa}]$ & $E_{+50^{\circ} \mathrm{C}}^{\prime}[\mathrm{MPa}]$ & $E_{+70^{\circ} \mathrm{C}}^{\prime}[\mathrm{MPa}]$ \\
\hline EHA_HG1_5_Mic10-170 $\mathrm{C}$ & 1145 & 1100 & 1085 & 1029 & 819 & 548 & 198 \\
EBA1_HG1_5_Mic10-170 ${ }^{\circ} \mathrm{C}$ & 2048 & 1975 & 1940 & 1910 & 1847 & 1758 & 1592 \\
EBA1_HG1_5_Mic10-180 ${ }^{\circ} \mathrm{C}$ & 2350 & 2277 & 2245 & 2214 & 2139 & 2020 & 1802 \\
EBA2_HG1_5_Mic10-170 $\mathrm{C}$ & 1760 & 1757 & 1740 & 1720 & 1652 & 1539 & 1103 \\
EBA2_HG1_5_Mic10-180 180 & 1900 & 1830 & 1800 & 1770 & 1700 & 1590 & 1390 \\
\hline
\end{tabular}

the sidewalls. Higher curing temperature results in increased brittleness of the composite.

3.2.3. Dynamic Mechanical Properties. In Table 3, the storage moduli for the analyzed self-healing formulations in a range of temperature between -30 and $70^{\circ} \mathrm{C}$ are compared. DMTA data show that the self-healing formulation based on the EHA epoxy matrix is characterized by mechanical parameters that may limit its use in applications where high glass transition temperature and modulus are needed. In fact, the storage 
modulus for EHA self-healing formulation is the lowest; the same consideration is also valid for the glass transition temperature.

EBA formulations show higher values of the elastic modulus in all investigated temperature range. At $70^{\circ} \mathrm{C}$, the lower value in the modulus (1103 $\mathrm{MPa}$ ) is shown by formulation EBA2 with $10 \%$ of microcapsules and a curing temperature of $170^{\circ} \mathrm{C}$. At the same temperature, EHA formulation shows a very low value of elastic modulus (198 MPa). Obviously, this value imposes limits on its applicability for temperature range greater than $50^{\circ} \mathrm{C}$. Data reported in Table 3 also show that, in all samples, an increase in the curing temperature produces an increase in the modulus values.

\subsubsection{Compression and Tensile versus Flexural Tests. Stress-} strain curves of the analyzed composites are dependent on the type of test. Almost all samples in tension fail in a brittle manner, while in compression the same material behaves as a ductile polymer with a yield point and higher elongation to break. Even the first linear parts of the curves are different. The maximum stresses determined in compression are 1.5-5 times higher than the tensile stresses measured for the same type of samples. This could be a reflection of the different stress fields that are applied, but it is more likely to be due to the occurrence of different molecular or small-scale processes that can occur in the different tests.

The tensile properties of brittle materials are largely determined by flaws and submicroscopic cracks. The cracks do not play such an important role in compression because the stresses tend to close the cracks rather than open them. Thus, compression tests tend to be characteristic of the pure polymer, while tension tests are more characteristic of the inhomogeneity in the material. In any case, for common polymer materials, the compressive strength of a brittle material should be 1.5 to 4 times its tensile strength [34]. It essentially means that our results are well in line with those generally found in continuous materials. In other words, the presence of capsules and catalyst does not influence the integrity of the materials. In particular, a good adhesion between the capsules and the polymer matrix is obtained during the curing process. In general, it prevents the dewetting of the capsules from the matrix and allows an efficient energy transfer during the crazing formation.

Flexural moduli calculated by DMA tests are higher than that measured in tensile tests. This is largely a result of both the nonlinearity of the stress-strain curve and the difference between compressive and tensile moduli. In flexural tests, in fact, part of the specimen is under tension and part is under compression. In addition, the so-called "skin effect" plays an important role for this type of test. The restrictions imposed by the walls of mold induce an excess of polymer at the sample surface. In flexural tests, where the maximum stress is at the surface, the properties of the surface are emphasized. Thus a skin more concentrated in polymer matrix can produce errors as large as 10 to $20 \%$ [34]. Another phenomenon that influences the modulus of a rigid composite is the temperature variations during the nonisothermal tests. Residual thermal stresses could be produced by the different thermal expansion coefficients of the several components of the self-healing

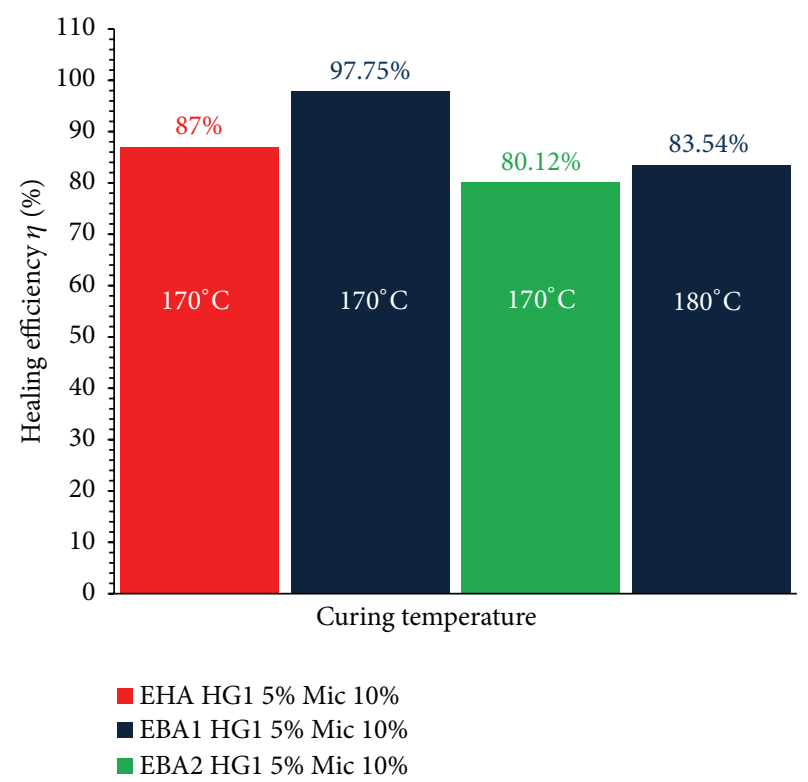

FIGURE 8: Comparison of healing efficiency for self-healing systems with different epoxy matrices (EHA, EBA1, and EBA2), at the different curing temperatures.

systems. In some cases, thermal stresses may be great enough to put the polymer in the nonlinear portion of its stress-strain curve. As the temperature is increased, the thermally induced stresses increase, so the relative modulus of the composite increases. In extreme cases, the observed relative modulus may be about two times the value expected from theory [34].

\section{Healing Efficiency}

The crack healing efficiency is calculated as the ratio of critical fracture loads for the healed and virgin samples. All formulations show high values in the healing efficiency (see Figure 8). The healing efficiency is found to be higher than 97\% [9]. Slightly lower efficiency is recorded for the EBA formulation cured up to $180^{\circ} \mathrm{C}$ [9]. All values of healing efficiency are affected by $5 \%$ error.

The high healing efficiency is another demonstration of the good adhesion between the capsules and the polymer matrix. It allows an effective cross-link formation along the sample and also prevents the dewetting of the microcapsules ensuring its efficient utilization during the crack propagation. The very high level of crack healing efficiency attained demonstrates the ability of the system to regenerate the pristine properties.

\section{Thermogravimetric Analysis of Self-Healing Samples}

Figure 9 shows the thermogravimetric curves in air of the analyzed self-healing formulations. The first stage of degradation is the same for the formulation EBA1 and EBA2. For EHA sample, thermal degradation starts at about $200^{\circ} \mathrm{C}$. EBA formulations are more stable with a starting degradation 


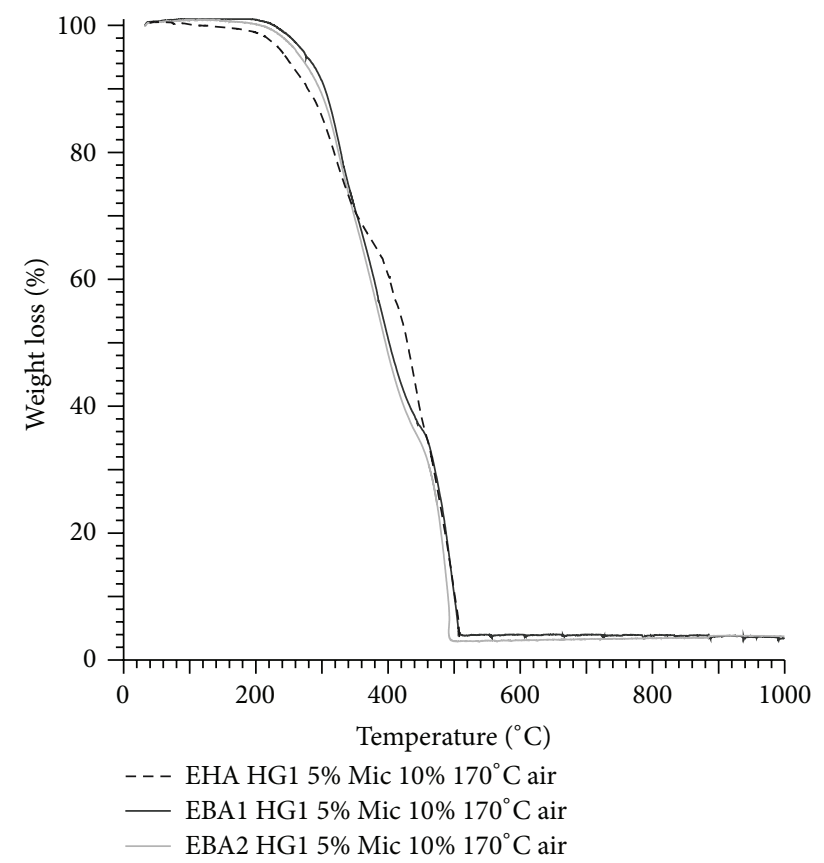

FIGURE 9: Thermogravimetric curves in air for self-healing systems with different epoxy matrices (EHA, EBA1, and EBA2).

at temperatures higher than $240^{\circ} \mathrm{C}$. Very similar results are obtained for the self-healing systems cured up to $180^{\circ} \mathrm{C}$.

In any case, all self-healing samples are stable and no thermal degradation occurs at temperatures where HG1 catalyst is still active. In fact, HG1 catalyst starts to deactivate at temperature around $180^{\circ} \mathrm{C}$, while the thermal degradation of the formulation starts at higher temperatures.

\section{Conclusions}

In this work, the mechanical properties of different selfhealing epoxy systems based on epoxy-resins and encapsulated ENB/Hoveyda-Grubbs 1st-generation catalyst are investigated. The matrix nature and the curing cycle play an important role in determining the mechanical properties of the resulting material. The investigated samples show a different stress-strain behavior, dependent on the type of stress applied. In tension the samples fail in a brittle manner, while in compression the same material behaves as a ductile polymer with a yield point and higher elongation to break. The maximum stresses determined in compression are 1.5-5 times higher than the tensile stresses recorded for the same type of samples. This behavior suggests a good adhesion between the capsules and the polymer matrix. The good adhesion achieved during the curing process is also confirmed by the high level of crack healing efficiency. The thermal analysis of the samples shows that all self-healing samples are stable for temperature where HG1 catalyst is active in ROMP.

In conclusion, the curing cycle and the chemical nature of the epoxy matrix can be chosen to obtain regenerative ability and mechanical performance in line with advanced applications.

\section{Conflict of Interests}

The authors declare that there is no conflict of interests regarding the publication of this paper.

\section{Acknowledgment}

The research leading to these results has received funding from the European Union Seventh Framework Programme (FP7/2007-2013) under Grant Agreement no. 313978.

\section{References}

[1] W. H. Binder, Self-Healing Polymers. From Principles to Applications, Wiley-VCH, Weinheim, Germany, 2013.

[2] S. R. White, N. R. Sottos, P. H. Geubelle et al., "Autonomic healing of polymer composites," Nature, vol. 409, no. 6822, pp. 794-797, 2001

[3] L. Guadagno, P. Longo, M. Raimondo et al., "Cure behavior and mechanical properties of structural self-healing epoxy resins," Journal of Polymer Science, Part B: Polymer Physics, vol. 48, no. 23, pp. 2413-2423, 2010.

[4] C. Dry and W. McMillan, "A novel method to detect crack location and volume in opaque and semi-opaque brittle materials," Smart Materials and Structures, vol. 6, no. 1, pp. 35-39, 1997.

[5] S. Burattini, B. W. Greenland, D. Chappell, H. M. Colquhoun, and W. Hayes, "Healable polymeric materials: a tutorial review," Chemical Society Reviews, vol. 39, no. 6, pp. 1973-1985, 2010.

[6] Y. C. Yuan, T. Yin, M. Z. Rong, and M. Q. Zhang, "Self healing in polymers and polymer composites. Concepts, realization and outlook: a review," Express Polymer Letters, vol. 2, no. 4, pp. 238 250, 2008.

[7] B. J. Blaiszik, S. L. B. Kramer, S. C. Olugebefola, J. S. Moore, N. R. Sottos, and S. R. White, "Self-healing polymers and composites," Annual Review of Materials Research, vol. 40, pp. 179-211, 2010.

[8] K. S. Toohey, N. R. Sottos, J. A. Lewis, J. S. Moore, and S. R. White, "Self-healing materials with microvascular networks," Nature Materials, vol. 6, no. 8, pp. 581-585, 2007.

[9] L. Guadagno, M. Raimondo, C. Naddeo, P. Longo, A. Mariconda, and W. H. Binder, "Healing efficiency and dynamic mechanical properties of self-healing epoxy systems," Smart Materials and Structures, vol. 23, no. 4, Article ID 045001, 11 pages, 2014.

[10] E. N. Brown, S. R. White, and N. R. Sottos, "Microcapsule induced toughening in a self-healing polymer composite," Journal of Materials Science, vol. 39, no. 5, pp. 1703-1710, 2004.

[11] J. D. Rule, N. R. Sottos, S. R. White, and J. S. Moore, "The chemistry of self-healing polymers," Education in Chemistry, vol. 42, no. 5, pp. 130-132, 2005.

[12] J. D. Rule, E. N. Brown, N. R. Sottos, S. R. White, and J. S. Moore, "Wax-protected catalyst microspheres for efficient self-healing materials," Advanced Materials, vol. 17, no. 2, pp. 205-208, 2005.

[13] A. S. Jones, J. D. Rule, J. S. Moore, S. R. White, and N. R. Sottos, "Catalyst morphology and dissolution kinetics of self-healing polymers," Chemistry of Materials, vol. 18, no. 5, pp. 1312-1317, 2006.

[14] M. R. Kessler and S. R. White, "Self-activated healing of delamination damage in woven composites," Composites Part A: Applied Science and Manufacturing, vol. 32, no. 5, pp. 683-699, 2001. 
[15] M. R. Kessler, N. R. Sottos, and S. R. White, "Self-healing structural composite materials," Composites Part A: Applied Science and Manufacturing, vol. 34, no. 8, pp. 743-753, 2003.

[16] E. N. Brown, S. R. White, and N. R. Sottos, "Retardation and repair of fatigue cracks in a microcapsule toughened epoxy composite-part I: manual infiltration," Composites Science and Technology, vol. 65, no. 15-16, pp. 2466-2473, 2005.

[17] E. N. Brown, S. R. White, and N. R. Sottos, "Retardation and repair of fatigue cracks in a microcapsule toughened epoxy composite-part II: in situ self-healing," Composites Science and Technology, vol. 65, no. 15-16, pp. 2474-2480, 2005.

[18] A. S. Jones, J. D. Rule, J. S. Moore, N. R. Sottos, and S. R. White, "Life extension of self-healing polymers with rapidly growing fatigue cracks," Journal of the Royal Society Interface, vol. 4, no. 13, pp. 395-403, 2007.

[19] G. O. Wilson, J. S. Moore, S. R. White, N. R. Sottos, and H. M. Andersson, "Autonomic healing of epoxy vinyl esters via ring opening metathesis polymerization," Advanced Functional Materials, vol. 18, no. 1, pp. 44-52, 2008.

[20] S. van der Zwaag, Self Healing Materials: An Alternative Approach to 20 Centuries of Materials Science, vol. 100 of Springer Series in Materials Science, Springer, Dordrecht, The Netherlands, 2007.

[21] C. Dry, "Multiple function, self-repairing composites with special adhesives," International Patent WO/2007/005657, 2007.

[22] M. Motuku, U. K. Vaidya, and G. M. Janowski, "Parametric studies on self-repairing approaches for resin infused composites subjected to low velocity impact," Smart Materials and Structures, vol. 8, no. 5, pp. 623-638, 1999.

[23] E. N. Brown, M. R. Kessler, N. R. Sottos, and S. R. White, "In situ poly(urea-formaldehyde) microencapsulation of dicyclopentadiene," Journal of Microencapsulation, vol. 20, no. 6, pp. 719-730, 2003.

[24] L. Guadagno, P. Longo, M. Raimondo et al., "Use of hoveydaGrubbs' second generation catalyst in self-healing epoxy mixtures," Composites Part B-Engineering, vol. 42, no. 2, pp. 296301, 2011.

[25] M. Raimondo and L. Guadagno, "Healing efficiency of epoxybased materials for structural application," in Proceedings of the 6th International Conference on Times of Polymers (Top) and Composites, vol. 1459, no. 1 of AIP Conference Proceedings, pp. 223-225, Ischia, Italy, June 2012.

[26] L. Guadagno, M. Raimondo, C. Naddeo et al., "Process for preparing self-healing composites materials of high efficiency for structural applications," Patent Publication no. US 2011118385 (A1), 2011.

[27] M. Raimondo and L. Guadagno, "Healing efficiency of epoxybased materials for structural applications," Polymer Composites, vol. 34, no. 9, pp. 1525-1532, 2013.

[28] L. Guadagno, M. Raimondo, C. Naddeo, P. Longo, and A. Mariconda, "Self-healing materials for structural applications," Polymer Engineering and Science, vol. 54, no. 4, pp. 777-784, 2014.

[29] L. Guadagno, M. Raimondo, C. Naddeo et al., "Dynamic mechanical properties of structural self-healing epoxy Resins," Applied Mechanics and Materials, vol. 62, pp. 95-105, 2011.

[30] M. Raimondo, P. Longo, A. Mariconda, and L. Guadagno, "Healing agent for the activation of self-healing function at low temperature," Advanced Composite Materials, vol. 24, no. 6, pp. 519-529, 2015.
[31] S. Mostovoy, P. B. Croseley, and E. J. Ripling, "Use of crack-lineloaded specimens for measuring plane-strain fracture toughness," Journal of Materials, vol. 2, no. 3, pp. 661-687, 1967.

[32] E. N. Brown, N. R. Sottos, and S. R. White, "Fracture testing of a self-healing polymer composite," Experimental Mechanics, vol. 42, no. 4, pp. 372-379, 2002.

[33] L. Guadagno, M. Raimondo, G. Iannuzzo, and S. Russo, "Selfhealing structures in aerospace applications," AIP Conference Proceedings, vol. 1255, no. 1, pp. 267-269, 2010.

[34] L. E. Nielsen and R. F. Landel, Mechanical Properties of Polymers and Composites, Marcel Dekker, New York, NY, USA, 2nd edition, 1994. 


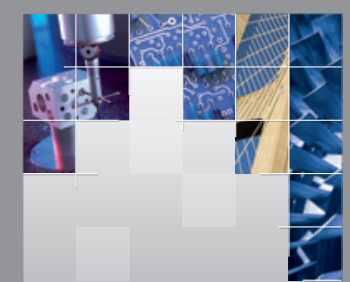

\section{Enfincering}
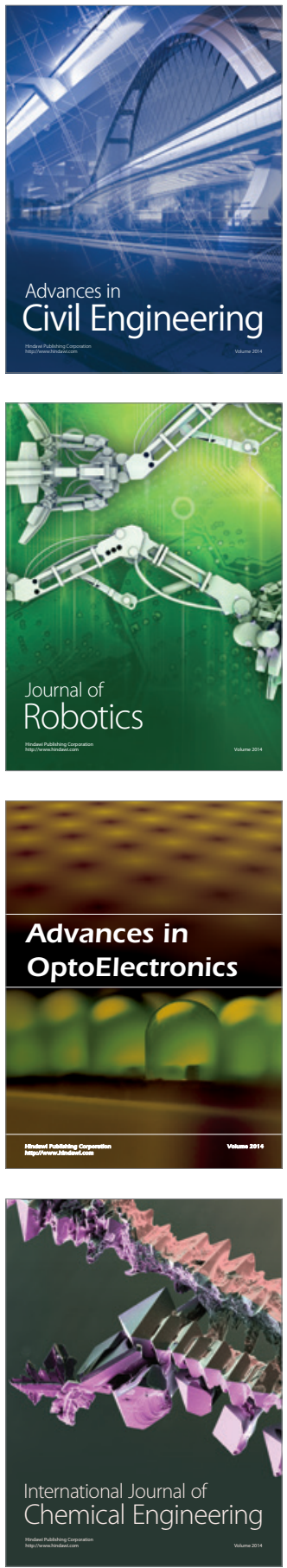

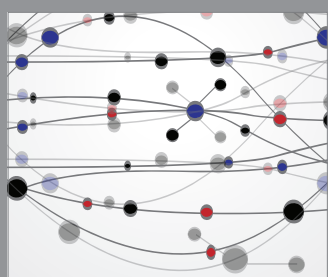

The Scientific World Journal

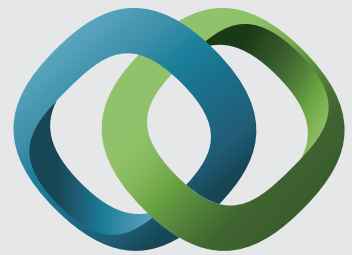

\section{Hindawi}

Submit your manuscripts at

http://www.hindawi.com
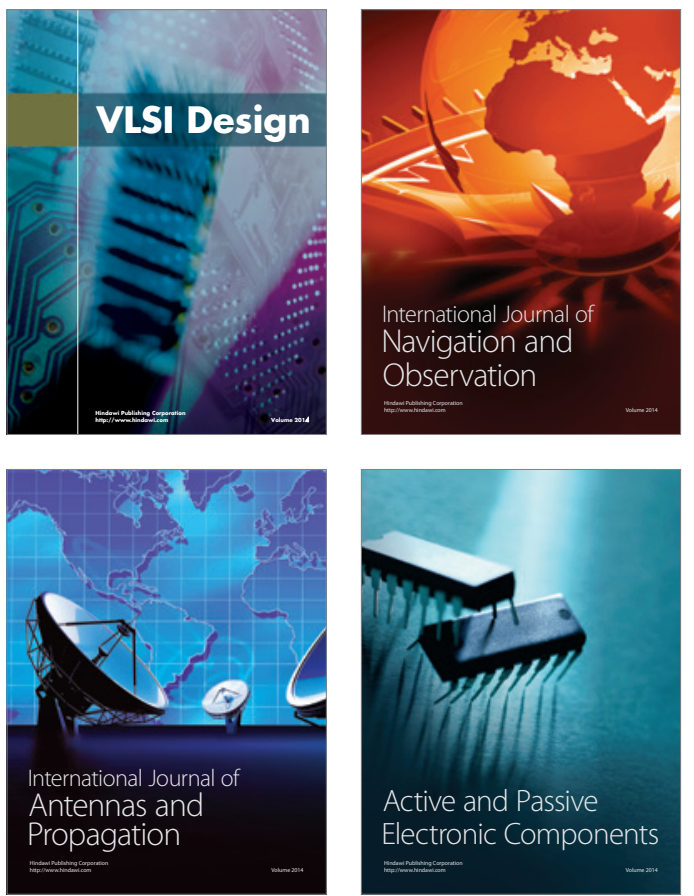
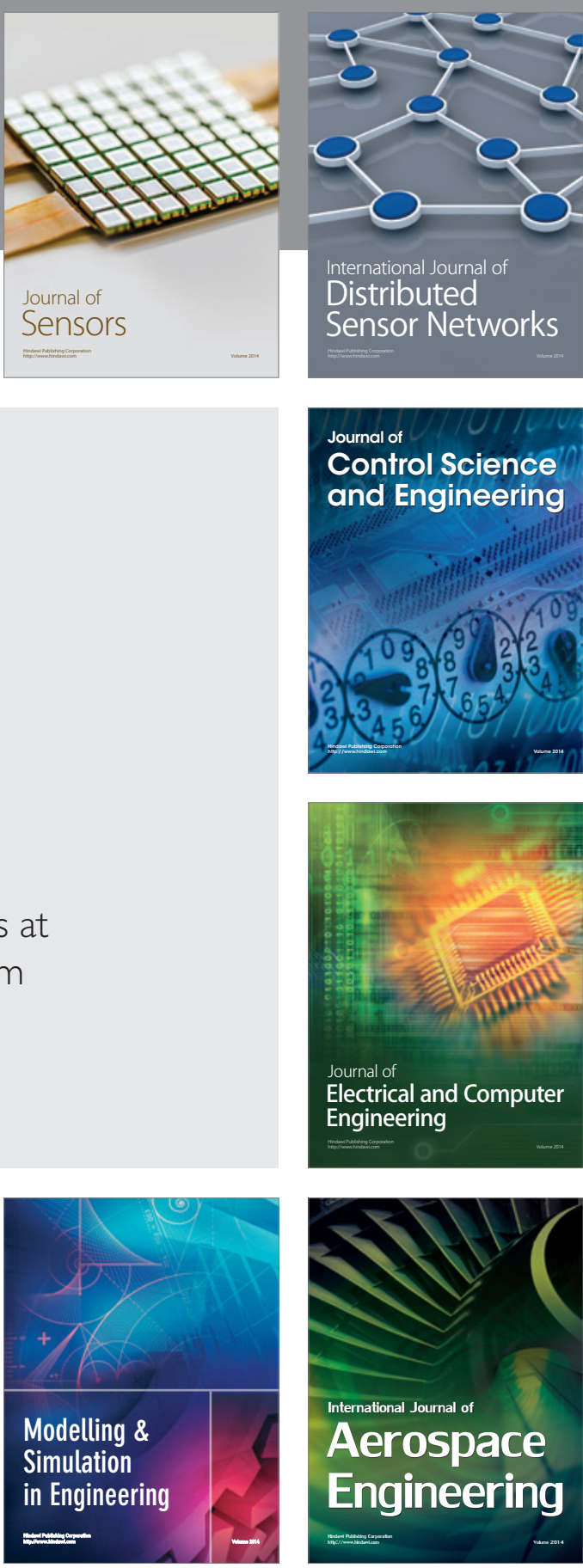

International Journal of

Distributed

Sensor Networks

Journal of

Control Science

and Engineering
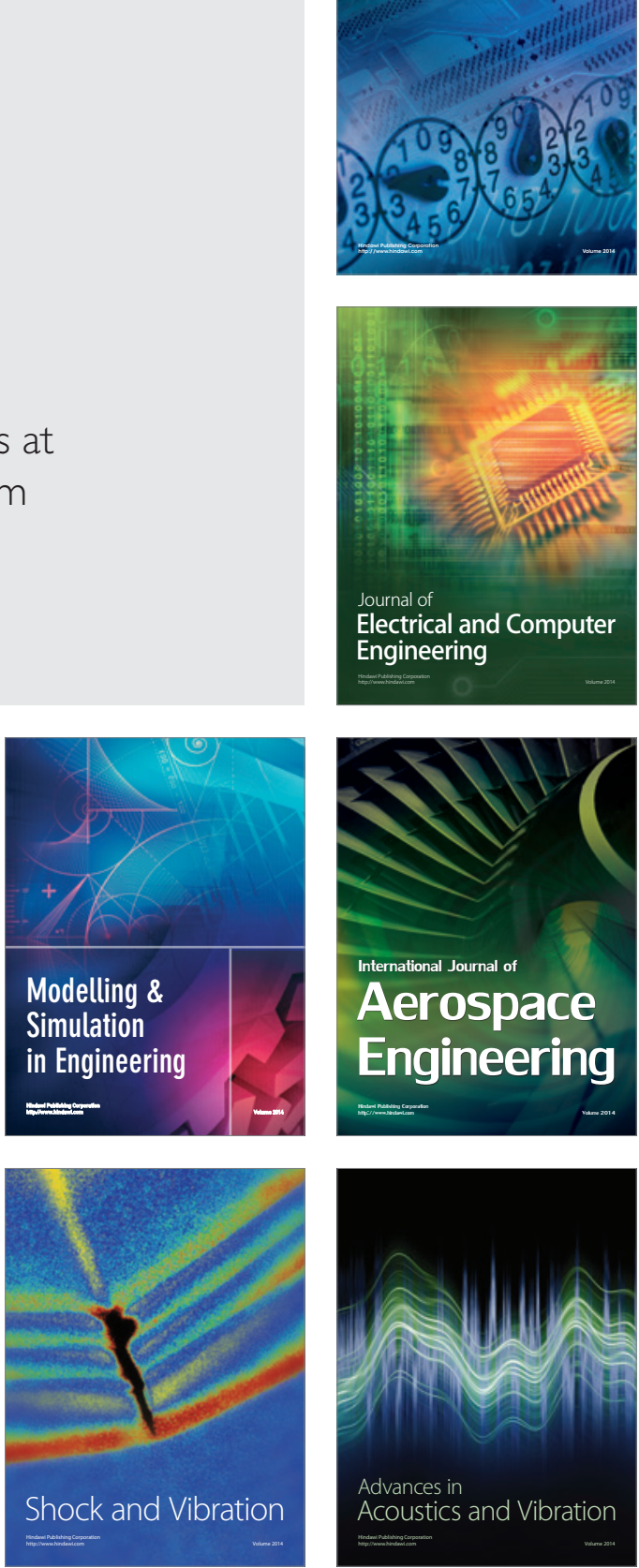